\title{
HLA class II alleles in human sporotrichosis in Mexican Amerindians
}

\author{
Guadalupe E. Estrada-Chávez ${ }^{1}$, Roberto Estrada ${ }^{2}$, Guadalupe Chavez $^{1}$, María-Elisa Vega Memije ${ }^{3}$, \\ Roberto Arenas Guzmán ${ }^{4}$, Maricela García-Lechuga ${ }^{5}$, Julio Granados ${ }^{5 *}$, Lucia Rangel-Gamboa ${ }^{6 *}$ \\ ${ }^{1}$ Dermatology Department, General Hospital de Acapulco, Guerrero, México; \\ ${ }^{2}$ Medicine Faculty, Universidad Autónoma de Guerrero, México; \\ ${ }^{3}$ Dermatology Department, General Hospital Dr. Manuel Gea González, Mexico City, México; \\ ${ }^{4}$ Medical Mycology Department, General Hospital Dr. Manuel Gea González, Mexico City, México. \\ ${ }^{5}$ Department of Transplantation, Inmunogenetics, Instituto Nacional de Ciencias Médicas y de la Nutrición, Salvador Zubirán, México; \\ ${ }^{6}$ Division of Investigation, General Hospital Dr. Manuel Gea González. Mexico City, México.
}

\begin{abstract}
Human leukocyte antigen (HLA) class II alleles are involved in antigen processing and presentation to T lymphocytes during fungal infections. However, few studies have investigated HLA genes in fungal diseases, or in sporotrichosis infections. Here, the frequencies of HLA-DR $\beta 1$ in 50 healthy volunteers and 9 patients with sporotrichosis from an endemic area in Mexico were determined to define their role in genetic susceptibility to this infection. Also, the frequencies of HLA-DR $\beta 1$ haplotypes were compared with a historic control group of healthy Mexican individuals. The patients presented that DR4 and DR8 increased, which were more than twice the control's values, whereas local controls (endemic area) presented DR*04:01 increased, compared with the control group from Mexico City. The data suggest that involvement of HLA antigens could affect the outcomes of the host-fungi interaction in sporotrichosis by regulating the immune response to Sporothrix schenckii complex.
\end{abstract}

Keywords: sporotrichosis, HLA class II , DR4, DR4 subtypes, DR*0401, DR8, Mexican mestizo

\section{INTRODUCTION}

Sporotrichosis is a re-emerging subacute or chronic subcutaneous mycosis that affects humans and some mammals, which is produced by the thermodimorphic fungi-Sporothrix schenckii(S. schenckii) complex. Sporotrichosis is considered an occupational

*Correspondence to: Lucia Rangel-Gamboa, Department of Ecology of Pathogenic Agents, Division of Investigation, General Hospital Dr. Manuel Gea González. Calzada de Tlalpan 4800, Tlalpan Centro I , Tlalpan, Ciudad de México, México. C.P 14080.Tel: 005240003000 ext. 6100, E-mail: draluciaragel@yahoo.com.mx; Julio Granados: Department of Transplantation, Inmunogenetics, Instituto Nacional de Ciencias Médicas y de la Nutrición, Salvador Zubirán. 7a Cerrada de Fray Pedro de Gante 50, disease that affects peasants, florists, farmers, carpenters and packers of crockery. It is a cosmopolitan disease that presents in tropical and subtropical countries and has been frequently reported in Latin America in recent decades ${ }^{[1]}$. In Mexico, sporotrichosis is considered the most common subcutaneous mycosis, with endemic areas in the states of Jalisco, Morelos, Puebla and Guerrero ${ }^{[2]}$. Sporotrichosis is observed in all age groups, but most frequently affects young adults. Epi-

\footnotetext{
Tlalpan, Sección X VI, 14080 Ciudad de México, México. Tel: 005255 5485-0080, E-mail: julgrate@yahoo.com.

Conflict of interests: No conflicts of interest have been reported. In addition, we confirm that none of the authors have any professional or financial relationship with the individuals who have been recommended to review the manuscript.
} 
demic outbreaks have been reported in Australia, the United States and México, with cases associated with contaminated hay, sphagnum moss and tent camping, respectively ${ }^{[3,4]}$. The infection is initiated by traumatic inoculation of contaminated organic material into the skin. The clinical presentation varies, and the fixed cutaneous form occurs when patients present with a unique nodular lesion, whereas the lymphocutaneous form is characterized by subcutaneous affection with lymphatic extension. Rare forms include primary lung, osteoarticular, ocular or disseminate infections ${ }^{[5,6]}$. In Mexico, the lymphocutaneous presentation is observed more frequently, follow by fixed cutaneous sporotrichosis, whereas the primary lung form is rare and likely associated with the genetic characteristics of the fungi and the human population affected in this country ${ }^{[7]}$. Thus, the clinical presentation has been associated with individual host susceptibility, immunology state, Sporothrix species and quantity of the inocu$\operatorname{lum}^{[8,9]}$. Dimorphic fungi, such as $S$. schenckii, assume both yeast and hyphal growth states based on the environmental conditions (temperature, $\mathrm{pH}$, etcetera). Thus, interactions with the mammalian microenvironment and immune system induce dimorphic transformation. T-cell-mediated immunity (CMI) is the main human response mechanism against $S$. schenckii complex ${ }^{[10]}$. The essential role of the CMI response is to destroy the fungi (or at least to limit the progression of infection) and produce an immunoprotective status against re-infection ${ }^{[11]}$. The immunological response to the disease is associated with a delayed hypersensitive response, in clinical practice evidenced by the sporotricin test ${ }^{[12]}$. Therefore, an interaction between pathogen recognition receptors (PRR) and pathogen associated molecular patterns (PAMPs) is necessary to trigger dendritic cells (DCs). The activated status of DC is characterized by cytokine production, costimulatory molecules and high MHC levels ${ }^{[13]}$. In other fungal infections as coccidiodomycosis, specific human leukocyte antigen (HLA) class II alleles have been associated with a predisposition to human infection $^{[14]}$; however, human leukocyte antigen Drelated (HLA-DR) allele associations have not been established in sporotrichosis. Therefore, the aim of this study was to investigate the association between HLA class II alleles and sporotrichosis in the Mexican Mestizo population, and to determine their roles in susceptibility or protection.

\section{MATERIALS AND METHODS}

\section{Subjects}

The study recruited a total of 9 patients with a clinical and laboratory diagnosis of sporotrichosis and 50 healthy controls, all of whom from "El Durazno"an endemic area of a sporotrichosis in Guerrero state, Mexico. Ethnically, the patients and controls were classified as Mestizos, who are defined as individuals born in Mexico, with Mexican ancestors dating to at least the third generation. Mestizos are the result of 500 years of admixture between Amerindians, Spaniards and/or Africans, and represent most of the Mexican population ${ }^{[15]}$. Also, alleles frequencies from El Durazno were compared with unrelated Mexican Mestizo individuals from Mexico City, who are considered representative of most of Mexico, since Mexico City is an important immigration center; and with historical data from the Mazatecans population, owing to its geographical proximity to "El Durazno". The protocol was reviewed and approved by the institution's Ethics Committee. Written informed consent was obtained from all subjects prior to their admission in this study, according to the Helsinki Declaration.

\section{HLA-DRß1 typing}

Genomic DNA from all subjects included in this study was purified from peripheral blood leukocytes, according to the method described by Miller. Blood was collected from a single peripheral venipuncture, according to the current guidelines and the procedures approved by the Ethics Internal Review Boards of the General Hospital "Dr. Manuel Gea González". The HLA-DR $\beta 1$ locus was genotyped based on the hybridization of labelled single-stranded polymerase chain reaction products to sequence-specific oligonucleotides, using the Life Codes HLA-DR $\beta 1$ Typing kit for use with Luminex (Gen-Probe Transplant Diagnostics, Inc., Stamford, CT, USA), following the manufacturer's recommendations. Data were analyzed using the Quicktype for Lifecodes version 3.0 software to determine the HLA alleles ${ }^{[16]}$.

\section{Intradermic test}

Sporotricin, a protein antigenic extract (obtained according to the technique described by DominguezSoto and Hojyo-Tomoka ${ }^{[17]}$ was used to perform the test. $100 \mu \mathrm{L}$ of this extract was applied intradermally to study the cellular responses in the patients and controls. The test was considered positive when the skin induration was equal to or greater than $5 \mathrm{~mm}$ between 24 and 48 hours post-inoculation ${ }^{[18]}$.

\section{Culture}

Skin lesion samples were incubated on Sabouraud 
Dextrose Agar (SDA) medium at $24{ }^{\circ} \mathrm{C}$. When macroscopically observed, a slow growing colony colored white to cream, moist and glabrous with a wrinkled and folded surface was seen. Older colony development demonstrated brown to black pigmentation on revers; microscopically, thin septate hyphae were observed, usually solitary with conidiophores arising at right angles; conidia were formed in clusters by sympodial proliferation at the apex of the conidiophore. As the culture ages, conidia are subsequently formed singly along the sides of both conidiophores and undifferentiated hyphae. Conidia are ovoid or triangular $(3 \sim 6 \times 2 \sim 3 \mu \mathrm{m})$, hyaline, and smoothwalled. Dimorphic capacity was demonstrated on a brain heart infusion (BHI) containing blood at $37^{\circ} \mathrm{C}$, with constant agitation, and glabrous colonies were observed (white to greyish-yellow and yeast-like, consisting of spherical or oval budding yeast cells).

\section{Statistical analysis}

The allele frequencies were calculated by direct counting, and the differences in the distribution of the alleles between patients and controls were analyzed using the odds ratios, $95 \%$ confidence interval and significance level. Statistically significant $P$ values $(\leqslant 0.05)$ were corrected, considering the number of alleles observed (pC). Statistical analyses were performed using the EPIINFO software, version 5.0 (USD incorporated 1990, Stone Mountain, GA, USA).

\section{RESULTS}

A total of 59 Mexican Mestizo individuals were included in the study and were genotyped for the HLADR $\beta 1$ locus; the patients with sporotrichosis included 8 females and 1 male, who ranged in age from 11 to 75 years. All patients were positive to intradermic tests and had skin indurations greater than $1 \mathrm{~cm}$ in diameter(Fig. 1). Patients had skin lesions with positive cultures for $S$. schenckii(Fig. 2). There were 50 healthy local controls ( 45 females and 5 males) ranging in age from 8 to 65 years, all without skin lesions and with negative intradermic tests. Table 1 summarizes the allelic frequency distributions of the HLADR $\beta 1$ alleles in the sporotrichosis patients and local controls from El Durazno. This population presented 6 HLA-DR $\beta 1$ alleles $(* 04, * 08, * 02, * 06, * 01$, $* 07$, in this order of frequency), and no alleles exhibited statistically significant differences in the frequency between the patients and local controls, but the frequency of the HLA-DR $\beta 1 * 04: 01$ and HLADR $\beta 1 * 08: 02$ alleles among sporotrichosis patients was more than twice that observed among the healthy controls from El Durazno. Thus, the allele frequencies from the El Durazno population (control group) were compared to the Mexican Mestizos' data (Table 2), showing a statistically significant difference in the frequency between the healthy controls from El Durazno and Mexican Mestizo historical data. The frequency of the HLA-DR*04:01 allele among the El Durazno controls was significantly higher compared to the Mexican Mestizo data $[P<0.0001$, OR: 19.4, 95\% confidence interval (CI): 2.4-156.0], when patients were compared with Mexican Mestizos, the difference in HLA-DR*04:01 was even higher (Table 3). In relation to the Mazatecan population HLA-DR*04:01 was not presented(Table 4), whereas for DR $\beta 1^{*} 08: 02$ there are not statistical differences, plus DR*16:02 was higher when compared with the El Durazno population $\left(\mathrm{pC}=1 \times 10^{-4}\right)$. When sporotrichosis patients were compared with Mazatecans population, $\mathrm{DR} * 08: 02$ is presented more than twice in patients, similar relation as exposed in sporotrichosis patients and healthy controls from "El Durazno" suggesting the veracity of this association. In relation to HLA-DR*04:01, the absence of this allele in Mazatecans population could be protect this group against $S$. schenckii complex infection (Table 5).

\section{DISCUSSION}

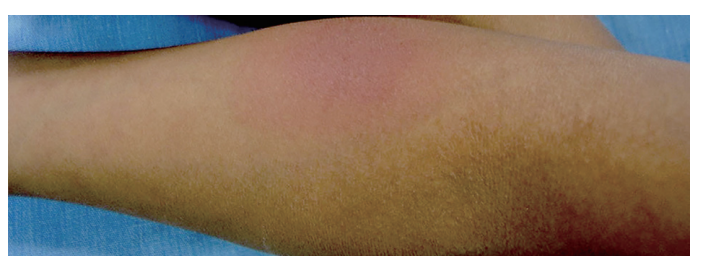

Fig.1 An intradermic test presented skin induration greater than $1 \mathrm{~cm}$ in diameter.
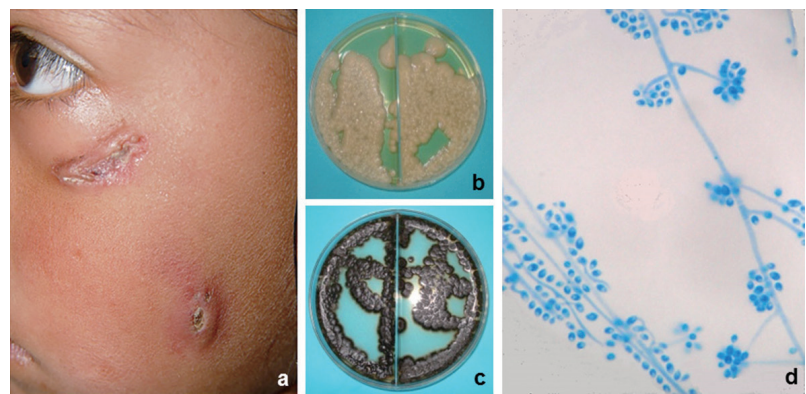

Fig.2 A young patient with facial skin lesions. a: gross observation of skin lesions; b: an SDA culture, a moist cream colony, with a wrinkled surface; c: an older colony with brown to black pigmentation; d: microscopically, the culture presented septate hyphae, with conidiophores and sympodial proliferation. 
Table 1 HLA-DRß1 allele frequencies in sporotrichosis patients and healthy controls from "E1 Durazno"

\begin{tabular}{|c|c|c|c|c|c|c|c|}
\hline \multirow{2}{*}{$\begin{array}{l}\text { HLA-DR } \\
\text { alleles }\end{array}$} & \multicolumn{2}{|c|}{$\begin{array}{c}\text { Patients with } \\
\text { sporotrichosis }(N=18)\end{array}$} & \multicolumn{2}{|c|}{$\begin{array}{l}\text { Healthy controls from } \\
\text { "El Durazno"(N=100) }\end{array}$} & \multirow[t]{2}{*}{$\mathrm{pC}^{*}$} & \multirow[t]{2}{*}{ OR } & \multirow[t]{2}{*}{$95 \%$ CI } \\
\hline & $n$ & g.f & $n$ & g.f & & & \\
\hline \multicolumn{8}{|l|}{ DR4 } \\
\hline $\mathrm{DR} * 04: 04$ & 1 & 0.05 & 9 & 0.09 & 0.63 & 0.59 & $0.07-5.00$ \\
\hline DR*04:01 & 4 & 0.22 & 9 & 0.09 & 0.10 & 2.24 & $0.62-8.09$ \\
\hline $\mathrm{DR} * 04: 07$ & 3 & 0.16 & 15 & 0.15 & 0.85 & 1.13 & $0.29-4.39$ \\
\hline OTHERS & NP & $\mathrm{NP}$ & 31 & 0.31 & 0.02 & 0.12 & $0.01-0.98$ \\
\hline \multicolumn{8}{|l|}{ DR8 } \\
\hline DR*08:02 & 5 & 0.27 & 12 & 0.12 & 0.08 & 2.82 & $0.85-9.31$ \\
\hline DR*08:04 & NP & $\mathrm{NP}$ & NP & $\mathrm{NP}$ & $\mathrm{NP}$ & $\mathrm{NP}$ & NP \\
\hline \multicolumn{8}{|l|}{ DR2 } \\
\hline DR*15:01 & 2 & 0.11 & 8 & 0.08 & 0.66 & 1.43 & $0.27-7.39$ \\
\hline DR*16:02 & 1 & 0.05 & 2 & 0.02 & 0.37 & 2.88 & $0.24-33.57$ \\
\hline OTHERS & NP & $\mathrm{NP}$ & NP & $\mathrm{NP}$ & $\mathrm{NP}$ & NP & NP \\
\hline \multicolumn{8}{|l|}{ DR6 } \\
\hline $\mathrm{DR} * 13 * 01$ & NP & NP & 1 & 0.01 & 0.37 & 2.88 & $0.24-33.57$ \\
\hline DR*14:02 & 1 & 0.05 & 8 & 0.08 & 0.72 & 0.67 & $0.07-5.76$ \\
\hline OTHERS & NP & $\mathrm{NP}$ & 1 & 0.01 & 0.37 & 2.88 & $0.24-33.57$ \\
\hline \multicolumn{8}{|l|}{ DR1 } \\
\hline DR*01:01 & 1 & 0.05 & 2 & 0.02 & 0.37 & 2.88 & $0.24-33.57$ \\
\hline DR*01:03 & NP & $\mathrm{NP}$ & 1 & 0.01 & 0.37 & 2.88 & $0.24-33.57$ \\
\hline \multicolumn{8}{|l|}{ DR7 } \\
\hline DR*07:01 & NP & NP & 1 & 0.01 & 0.37 & 2.88 & $0.24-33.57$ \\
\hline \multicolumn{8}{|l|}{ DR5 } \\
\hline DR*11:01 & NP & NP & NP & NP & NP & NP & NP \\
\hline $\mathrm{DR}^{*} 11: 04$ & NP & NP & NP & NP & NP & NP & NP \\
\hline $\mathrm{DR} * 12: 01$ & NP & NP & NP & $\mathrm{NP}$ & NP & NP & NP \\
\hline OTHERS & NP & NP & NP & NP & NP & NP & NP \\
\hline \multicolumn{8}{|l|}{ DR3 } \\
\hline DR*03:01 & NP & NP & NP & NP & NP & NP & NP \\
\hline OTHERS & NP & NP & NP & NP & NP & NP & NP \\
\hline \multicolumn{8}{|l|}{ DR9 } \\
\hline DR*09:01 & NP & NP & NP & NP & NP & NP & NP \\
\hline \multicolumn{8}{|l|}{ DR10 } \\
\hline DR10:01 & NP & NP & NP & NP & NP & NP & NP \\
\hline
\end{tabular}

$N$ : number of individuals; $n$ : number of alleles; g.f: gene frenquencies; *pC by Mantel- Haenszel method; OR: odds ratios; CI: confidence interval; NP: not presented.

Sporotrichosis is the most common subcutaneous mycosis in Mexico and is considered a remerging disease worldwide, particularly in Latin-American countries. The mycosis is classified as an occupational disease that particularly affects farmers ${ }^{[19]}$. Mexican peasants who live in endemic areas and use sandals are constantly exposed to $S$. schenckii-a fungus that lives in soil and organic materials ${ }^{[18]}$. "El Durazno", Guerrero, is considered an endemic area for sporotrichosis, where the environmental characteristics of the area and the use of natural materials in many local houses provide a suitable condition for the development of the disease ${ }^{[20]}$.

The cellular immune response plays an important part in host interaction with S. schenckii. The failure of cellular immune response or loss of balance among the components involved permits fungal dissemination and progression of the infection ${ }^{[21]}$. In human immunity, the HLA system contributes to the presentation of pathogen-derived peptides to $\mathrm{T}$ cells. The role of HLA-DR in fungal infections was described in chromoblastomycosis, where DCs from infected patients exhibited an increased expression of HLA-DR ${ }^{[22]}$.

Our data showed an increased rate of HLADR $\beta 1 * 04: 01$ and HLA-DR $\beta 1 * 08: 02$ alleles among sporotrichosis patients, which was more than twice that observed among healthy controls from El Durazno (Table 1). The result suggests that polymorphisms in the MHC genes increase susceptibility to sporotrichosis. Furthermore, HLA-DR $\beta 1^{*} 08$ has been reported to be associated with susceptibility to onychomycosis and other infections such as tuberculosis. In pulmonary tuberculosis HLA-DR $\beta 1 * 08: 03$ 
Table 2 HLA-DRß1 allele frequencies from "El Durazno" healthy controls and Mexican mestizo historical data

\begin{tabular}{|c|c|c|c|c|c|c|c|}
\hline \multirow{2}{*}{$\begin{array}{l}\text { HLA-DR } \\
\text { alleles }\end{array}$} & \multicolumn{2}{|c|}{$\begin{array}{l}\text { Healthy controls from "El } \\
\text { Durazno" }(N=100)\end{array}$} & \multicolumn{2}{|c|}{$\begin{array}{l}\text { Mexican mestizos } \\
\qquad(N=198)\end{array}$} & \multirow[t]{2}{*}{$\mathrm{pC}^{*}$} & \multirow[t]{2}{*}{ OR } & \multirow[t]{2}{*}{$95 \% \mathrm{CI}$} \\
\hline & $n$ & g.f & $n$ & g.f & & & \\
\hline \multicolumn{8}{|l|}{ DR4 } \\
\hline $\mathrm{DR} * 04: 04$ & 9 & 0.09 & 9 & 0.04 & 0.120 & 2.07 & $0.79-5.40$ \\
\hline DR*04:01 & 9 & 0.09 & 1 & 0.00 & $1 \times 10^{-4}$ & 19.40 & $2.40-156.00$ \\
\hline DR*04:07 & 15 & 0.15 & 21 & 0.10 & 0.272 & 1.48 & $0.73-3.02$ \\
\hline OTHERS & 31 & 0.31 & 16 & 0.08 & $1 \times 10^{-6}$ & 5.11 & $2.63-9.92$ \\
\hline \multicolumn{8}{|l|}{ DR8 } \\
\hline DR*08:02 & 12 & 0.12 & 30 & 0.15 & 0.461 & 0.76 & $0.37-1.56$ \\
\hline DR*08:04 & NP & $\mathrm{NP}$ & 3 & 0.01 & & & \\
\hline \multicolumn{8}{|l|}{ DR2 } \\
\hline DR*15:01 & 8 & 0.08 & 9 & 0.04 & 0.225 & 1.82 & $0.68-4.88$ \\
\hline DR*16:02 & 2 & 0.02 & 3 & 0.01 & 0.750 & 1.32 & $0.21-8.07$ \\
\hline OTHERS & NP & NP & 6 & 0.03 & 0.200 & 0.27 & $0.03-2.27$ \\
\hline \multicolumn{8}{|l|}{ DR6 } \\
\hline $\mathrm{DR} * 13^{*} 01$ & 1 & 0.01 & 4 & 0.02 & 0.510 & 0.48 & $0.05-4.44$ \\
\hline DR*14:02 & 8 & 0.08 & 7 & 0.03 & 0.120 & 2.22 & $0.78-6.32$ \\
\hline OTHERS & 1 & 0.01 & 20 & 0.10 & 0.003 & 0.08 & $0.01-0.68$ \\
\hline \multicolumn{8}{|l|}{ DR1 } \\
\hline DR*01:01 & 2 & 0.02 & 7 & 0.03 & 0.460 & 0.55 & $0.11-2.73$ \\
\hline DR*01:03 & 1 & 0.01 & 3 & 0.01 & 0.710 & 0.65 & $0.06-6.39$ \\
\hline \multicolumn{8}{|l|}{ DR7 } \\
\hline DR*07:01 & 1 & 0.01 & 22 & 0.11 & 0.002 & 0.08 & $0.01-0.60$ \\
\hline \multicolumn{8}{|l|}{ DR5 } \\
\hline DR*11:01 & NP & NP & 12 & 0.06 & 0.030 & 0.14 & $0.01-1.11$ \\
\hline DR*11:04 & NP & NP & 4 & 0.02 & 0.370 & 0.38 & $0.04-3.38$ \\
\hline $\mathrm{DR} * 12: 01$ & NP & NP & 2 & 0.01 & 0.710 & 0.65 & $0.06-6.39$ \\
\hline OTHERS & NP & NP & 4 & 0.02 & 0.370 & 0.38 & $0.04-3.38$ \\
\hline \multicolumn{8}{|l|}{ DR3 } \\
\hline DR*03:011 & NP & NP & 9 & 0.04 & 0.080 & 0.18 & $0.02-1.50$ \\
\hline OTHERS & NP & NP & 2 & 0.01 & 0.710 & 0.65 & $0.06-6.39$ \\
\hline \multicolumn{8}{|l|}{ DR9 } \\
\hline DR*09:01 & NP & NP & 3 & 0.01 & 0.510 & 0.48 & $0.05-4.44$ \\
\hline \multicolumn{8}{|l|}{ DR10 } \\
\hline DR10:01 & NP & NP & 1 & 0.00 & 0.990 & 0.98 & $0.08-11.05$ \\
\hline
\end{tabular}

$N$ : number of individuals; $n$ : number of alleles; g.f: gene frenquencies; *pC by Mantel- Haenszel method; OR: odds ratios; CI: confidence interval; NP: not presented.

has been strongly associated with drug resistance, disease severity and disease recurrence in the Asian population. It has been suggested that HLA alleles influence susceptibility to fungal infections, such as histoplasmosis, chromoblastomycosis, paracoccidioidomycosis and a severe form of coccidioidomyco$\operatorname{sis}^{[23]}$. HLA-DR*08 allele has also been associated with genetic susceptibility to develop onychomycosis in the Mexican Mestizo population ${ }^{[24]}$. Moreover, our data showed that the HLA-DR*04:01 subtype was increased in the El Durazno patients, this value is interesting considering the high frequency of HLADR*04:01 among Durazno population when they are compared with other Mexican groups, suggesting that in the El Durazno population, HLA-DR*04:01 could serve also as susceptibility factor for development $S$. schenckii fungal infection, and could be explained (at least in part) the particular endemicity of the sporotrichosis infection in this area. In contrast, some HLA alleles have also been associated with resistance to specific cutaneous fungal infections, as is the case for dermatophytosis ${ }^{[25]}$.

The HLA-DR4 subtype distribution in Mexican populations, which presented variance according to geography and ethnic origins, is exposed in Table 2 and Table 4, where we compared healthy controls from El Durazno with Mexican Mestizo and with the Mazatecan population. In order to comprehend the possible HLA-DR*04:01 susceptibility mechanism and considering that variance in peptide affinity has been described for DR4 subtypes, it is necessary to characterize HLA-DR4 subtypes in a larger number of patients and controls, plus study tridimensional conformation and molecular affinity for several peptides to understand the role of HLA-DR4 allele subtypes in sporotrichosis susceptibility. 
Table 3 Gene frequencies of HLA-DRß1 alleles in patients with sporotrichosis and healthy historical controls

\begin{tabular}{|c|c|c|c|c|c|c|c|}
\hline \multirow{2}{*}{$\begin{array}{c}\text { HLA-DR } \\
\text { alleles }\end{array}$} & \multicolumn{2}{|c|}{$\begin{array}{c}\text { Patients with } \\
\text { sporotrichosis }(N=18)\end{array}$} & \multicolumn{2}{|c|}{$\begin{array}{l}\text { Mexican mestizo } \\
\text { controls }(N=198)\end{array}$} & \multirow[t]{2}{*}{$\mathrm{pC}^{*}$} & \multirow[t]{2}{*}{ OR } & \multirow[t]{2}{*}{$95 \%$ CI } \\
\hline & $n$ & g.f & $n$ & g.f & & & \\
\hline \multicolumn{8}{|l|}{ DR4 } \\
\hline DR*04:04 & 1 & 0.05 & 9 & 0.045 & 0.83 & 1.24 & $0.14-10.44$ \\
\hline DR*04:01 & 4 & 0.22 & 1 & 0.005 & $1 \times 10^{-6}$ & 56.28 & $5.88-537.00$ \\
\hline DR*04:07 & 3 & 0.16 & 21 & 0.106 & 0.43 & 1.68 & $0.45-6.30$ \\
\hline OTHERS & NP & NP & 16 & 0.080 & & & \\
\hline \multicolumn{8}{|l|}{ DR8 } \\
\hline DR*08:02 & 5 & 0.27 & 30 & 0.150 & 0.16 & 2.15 & $0.71-6.48$ \\
\hline DR*08:04 & NP & NP & 3 & 0.015 & & & \\
\hline \multicolumn{8}{|l|}{ DR2 } \\
\hline DR*15:01 & 2 & 0.11 & 9 & 0.045 & 0.22 & 2.62 & $0.52-13.19$ \\
\hline DR*16:02 & 1 & 0.05 & 3 & 0.015 & 0.22 & 3.82 & $0.37-38.78$ \\
\hline OTHERS & NP & NP & 6 & 0.030 & 0.66 & 1.60 & $0.18-13.82$ \\
\hline \multicolumn{8}{|l|}{ DR6 } \\
\hline $\mathrm{DR} * 13 * 01$ & NP & NP & 4 & 0.020 & 0.45 & 2.27 & $0.25-20.56$ \\
\hline $\mathrm{DR} * 14: 02$ & 1 & 0.05 & 7 & 0.035 & 0.66 & 1.60 & $0.18-13.82$ \\
\hline OTHERS & NP & NP & 20 & 0.101 & 0.49 & 0.49 & $0.06-3.91$ \\
\hline \multicolumn{8}{|l|}{ DR1 } \\
\hline DR*01:01 & 1 & 0.05 & 7 & 0.050 & 0.66 & 1.60 & $0.18-13.82$ \\
\hline DR*01:03 & NP & NP & 3 & 0.015 & 0.34 & 2.85 & $0.30-26.97$ \\
\hline \multicolumn{8}{|l|}{ DR7 } \\
\hline DR*07:01 & NP & NP & 22 & 0.111 & 0.43 & 0.44 & $0.05-3.52$ \\
\hline \multicolumn{8}{|l|}{ DR5 } \\
\hline DR*11:01 & NP & NP & 12 & 0.060 & 0.86 & 0.83 & $0.10-6.79$ \\
\hline DR*11:04 & NP & NP & 4 & 0.020 & 0.45 & 2.27 & $0.25-20.56$ \\
\hline $\mathrm{DR}^{*} 12: 01$ & NP & NP & 2 & 0.010 & 0.22 & 3.82 & $0.37-38.78$ \\
\hline OTHERS & NP & NP & 4 & 0.020 & 0.45 & 2.27 & $0.25-20.56$ \\
\hline \multicolumn{8}{|l|}{ DR3 } \\
\hline DR*03:01 & NP & NP & 9 & 0.045 & 0.92 & 1.10 & $0.13-9.16$ \\
\hline OTHERS & NP & NP & 2 & 0.010 & 0.11 & 5.76 & $0.49-66.87$ \\
\hline \multicolumn{8}{|l|}{ DR9 } \\
\hline DR*09:01 & NP & NP & 3 & 0.015 & 0.22 & 3.82 & $0.37-38.78$ \\
\hline \multicolumn{8}{|l|}{ DR10 } \\
\hline DR10:01 & NP & NP & 1 & 0.005 & 0.11 & 5.76 & $0.49-66.87$ \\
\hline
\end{tabular}

$N$ : number of individuals; $n$ : number of alleles; g.f: gene frenquencies; *pC by Mantel- Haenszel method; OR: odds ratios; CI: confidence interval; NP: not presented.

\section{Acknowledgements}

Our sincere thanks to the Dermatology Community (Dermatología comunitaria) in Acapulco Guerrero, who contributed to the recollection of blood samples.

\section{References}

[1] Evangelista M, Almeida R, Meideiros M, et al. Phenotypic and Molecular Identification of Sporothrix isolates from an epidemic area of sporotichosis in Brazil. Mycopathologia, 2011,172(4):257-67.

[2] Macotela-Ruiz E, Nochebuena-Ramos E. Sporotrichosis in rural populations of North mountains of Puebla State, 55 cases informed from September 1995 to December 2005. Gac Méd Méx(in Spanish), 2006,142(5):377-80.

[3] Feeney KT, Arthur IH, Whittle AJ, et al. Outbreak of sporotrichosis, Wester Australia. Emer Infec Dis, 2007,13(8):1228-31.

[4] O' Reilly LC, Altman SA. Macrorestriction analysis of clinical and environmental isolates of Sporothrix schenckii. J Clin Microbiol, 2006,44(7):2547-52.

[5] Costa RO, de Mesquita KC, Damasco PS, et al. Infectious arthritis as the single manifestation of sporotrichosis: $\mathrm{Se}-$ rology from serum and synovial fluid samples as an aid to diagnosis. Rev Iberoam Micol, 2008,25(1):54-6.

[6] Zhang Z, Liu X, Lü X, et al. Variation in genotype and higher virulence of a strain of Sporothrix schenckii causing disseminated cutaneous sporotrichosis. Mycopathologia,2011,172(6):439-46.

[7] Rangel-Gamboa L, Martinez-Hernandez F, Maravilla $\mathrm{P}$, et al. Update of phylogenetic and genetic diversity of Sporothrix schenckii sensu lato. Med Myc, 2016,54(3):248-55.

[8] Arrillaga-Moncrieff I, Capilla J, Mayayo E, et al. Different virulence levels of the species of Sporothrix in a murine model. Clin Microbiol Infect, 2009,15(7):651-5.

[9] Caspeta L, Nielsen J. Thermotolerant yeast strains adapted by laboratory evolution show trade-off at ancestral temperatures and preadaptation to other stresses. 
Table 4 HLA-DRß1 allele frequencies from "El Durazno" healthy controls and Mazatecans

\begin{tabular}{|c|c|c|c|c|c|c|c|}
\hline \multirow{2}{*}{$\begin{array}{l}\text { HLA-DR } \\
\text { alleles }\end{array}$} & \multicolumn{2}{|c|}{$\begin{array}{l}\text { Healthy controls from "El } \\
\text { Durazno" }(N=100)\end{array}$} & \multicolumn{2}{|c|}{$\begin{array}{l}\text { Mazatecans } \\
(N=142)\end{array}$} & \multirow[t]{2}{*}{$\mathrm{pC}^{*}$} & \multirow[t]{2}{*}{ OR } & \multirow[t]{2}{*}{$95 \%$ CI } \\
\hline & $n$ & g.f & $n$ & gf & & & \\
\hline \multicolumn{8}{|l|}{ DR4 } \\
\hline $\mathrm{DR} * 04: 04$ & 9 & 0.09 & 14 & 0.09 & 0.82 & 0.90 & $0.37-2.17$ \\
\hline DR*04:01 & 9 & 0.09 & NP & NP & $6 \times 10^{-4}$ & 15.66 & $1.97-124.47$ \\
\hline DR*04:07 & 15 & 0.15 & 40 & 0.28 & 0.01 & 0.45 & $0.23-0.87$ \\
\hline OTHERS & 31 & 0.31 & 15 & 0.10 & $1 \times 10^{-4}$ & 3.80 & $1.92-7.52$ \\
\hline \multicolumn{8}{|l|}{ DR8 } \\
\hline DR*08:02 & 12 & 0.12 & 19 & 0.13 & 0.75 & 0.88 & $0.40-1.91$ \\
\hline DR*08:04 & NP & NP & NP & NP & NP & NP & NP \\
\hline \multicolumn{8}{|l|}{ DR2 } \\
\hline DR*15:01 & 8 & 0.08 & NP & NP & $1 \times 10^{-3}$ & 13.94 & $1.73-111.93$ \\
\hline DR*16:02 & 2 & 0.02 & 26 & 0.18 & $1 \times 10^{-4}$ & 0.09 & $0.02-0.39$ \\
\hline OTHERS & NP & $\mathrm{NP}$ & 7 & 0.04 & 0.091 & 0.19 & $0.02-1.59$ \\
\hline \multicolumn{8}{|l|}{ DR6 } \\
\hline $\mathrm{DR} * 13 * 01$ & 1 & 0.01 & NP & NP & 0.37 & 2.87 & $0.25-32.17$ \\
\hline $\mathrm{DR}^{*} 14: 02$ & 8 & 0.08 & 5 & 0.03 & 0.12 & 2.38 & $0.75-7.50$ \\
\hline OTHERS & 1 & 0.01 & 12 & 0.08 & 0.01 & 0.10 & $0.01-0.85$ \\
\hline \multicolumn{8}{|l|}{ DRl } \\
\hline DR*01:01 & 2 & 0.02 & 1 & 0.007 & 0.37 & 2.8 & $0.25-32.17$ \\
\hline DR*01:03 & 1 & 0.01 & NP & NP & & & \\
\hline \multicolumn{8}{|l|}{ DR7 } \\
\hline DR*07:01 & 1 & 0.01 & 1 & 0.007 & 0.80 & 1.42 & $0.088-23.04$ \\
\hline \multicolumn{8}{|l|}{ DR5 } \\
\hline DR*11:01 & NP & NP & 1 & 0.007 & 0.77 & 0.70 & $0.06-7.90$ \\
\hline DR*11:04 & NP & NP & NP & NP & NP & NP & NP \\
\hline $\mathrm{DR} * 12: 01$ & NP & NP & NP & NP & NP & NP & NP \\
\hline OTHERS & NP & NP & NP & NP & NP & NP & NP \\
\hline \multicolumn{8}{|l|}{ DR3 } \\
\hline DR*03:011 & NP & NP & NP & NP & NP & NP & NP \\
\hline OTHERS & NP & NP & NP & NP & NP & NP & NP \\
\hline \multicolumn{8}{|l|}{ DR9 } \\
\hline DR*09:01 & NP & NP & NP & NP & NP & NP & NP \\
\hline \multicolumn{8}{|l|}{ DR10 } \\
\hline DR10:01 & NP & NP & 1 & 0.007 & 0.77 & 0.70 & $0.06-7.90$ \\
\hline
\end{tabular}

$N$ : number of individuals; $n$ : number of alleles; g.f: gene frenquencies; *pC by Mantel- Haenszel method; OR: odds ratios; CI: confidence interval; NP: not presented.

MBio,2015,6(4):e00431-15.

[10] Guzman-Beltran S, Perez-Torres A, Coronel-Cruz C, et al.Phagocytic receptors on macrophages distinguish between different Sporothrix schenckii morphotypes. Microb Infect, 2012,14(12):1093-101.

[11] Bourgeois C, Majer O, Frohner IE, et al. Fungal attacks on mammalian host: pathogen elimination requires sensing and tasting. Curr Opin Microbiol, 2010,13(4):401-8.

[12] Blanco J, Garcia M. Immune response to fungal infections. Vet Immunol Immunopath, 2008,125(1-2):47-70.

[13] Verdan FF, Faleiros JC, Ferreira LS, et al. Dendritic cell are able to differentially recognize Sporothrix schenckii antigens and promote $\mathrm{TH} 1 / \mathrm{Th} 17$ response in vitro. Immunobiol, 2012,217(8):788-94.

[14] Louie L, Ng S, Hajjeh R,et al. Influence of host genetics on the severity of coccidioidomycosis. Emerg Infect Dis, 1999,5(5):672-80.

[15] Rubi-Castellasnos R, Anaya-Palafox M, Mena-Rojas E, et al. Genetic data of 15 autosomal STRs (identifier kit) of three Mexican Mestizo population samples from the states of Jalisco (west), Puebla (Center), and Yucatan (Southeast). Forensic Sci Int Genet, 2009,3(3):e71-6.

[16] Escamilla-Tilch M, Torre-Carrillo NM, Payan RR, et al. Association of genetic polymorphism of HLA-DRB1 antigens with the susceptibility to lepromatous leprosy. Biomed Rep, 2013,1(6):945-9.

[17] Dominguez-Soto L, Hojyo-Tomoka T. The intradermal sporotrichin test and the diagnosis of sporotrichosis. Int $J$ Dermatol, 1983,22(9):520.

[18] Sánchez-Alemán MA, Araiza J, Bonifaz A. Isolation and characterization of wild Sporothrix schenckii strains and investigation of sporotrichina reactors. Gac Med Mex (in Spanish), 2004,140(5):507-12.

[19] Messias-Rodrigues A, De Hoog S, Pires de Camargo Z. Emergence of pathogenecity in the Sporothrix schenckii complex. Med Myc, 2013,51(4):405-12.

[20] Carrada Bravo T. Esporotricosis: Avancesrecientesen el diagnóstico de laboratorio, histopatología y la epidemiologíaen México. Rev Latinoamer Patol Clin(in Spanish), 2012,59(3):147-71. 
Table 5 Gene frequencies of HLA-DRß1 alleles in patients with sporotrichosis and Mazatecans

\begin{tabular}{|c|c|c|c|c|c|c|c|}
\hline \multirow[t]{2}{*}{ HLA-DR } & \multicolumn{2}{|c|}{$\begin{array}{c}\text { Patients with } \\
\text { sporotrichosis }(N=18)\end{array}$} & \multicolumn{2}{|c|}{$\begin{array}{l}\text { Mazatecans } \\
(N=142)\end{array}$} & \multirow[t]{2}{*}{$\mathrm{pC}^{*}$} & \multirow[t]{2}{*}{ OR } & \multirow[t]{2}{*}{$95 \% \mathrm{CI}$} \\
\hline & $n$ & g.f & $n$ & g.f & & & \\
\hline \multicolumn{8}{|l|}{ DR4 } \\
\hline $\mathrm{DR} * 04: 04$ & 1 & 0.05 & 14 & 0.09 & 0.55 & 0.53 & $0.066-4.35$ \\
\hline $\mathrm{DR} * 04: 01$ & 4 & 0.22 & NP & NP & $1 \times 10^{-4}$ & 54.3 & $5.88-499.8$ \\
\hline DR*04:07 & 3 & 0.16 & 40 & 0.28 & 0.30 & 0.51 & $0.14-1.85$ \\
\hline OTHERS & NP & NP & 15 & 0.10 & 0.46 & 0.46 & $0.05-3.71$ \\
\hline \multicolumn{8}{|l|}{ DR8 } \\
\hline DR*08:02 & 5 & 0.27 & 19 & 0.13 & 0.10 & 2.48 & $0.79-7.77$ \\
\hline DR*08:04 & NP & $\mathrm{NP}$ & NP & NP & NP & NP & NP \\
\hline \multicolumn{8}{|l|}{ DR2 } \\
\hline DR*15:01 & 2 & 0.11 & $\mathrm{NP}$ & NP & $1 \times 10^{-4}$ & 28.2 & $2.75-288.38$ \\
\hline DR*16:02 & 1 & 0.05 & 26 & 0.18 & 0.17 & 0.26 & $0.03-2.06$ \\
\hline OTHERS & NP & $\mathrm{NP}$ & 7 & 0.04 & 0.98 & 0.98 & $0.11-8.36$ \\
\hline \multicolumn{8}{|l|}{ DR6 } \\
\hline $\mathrm{DR} * 13 * 01$ & NP & $\mathrm{NP}$ & NP & NP & NP & NP & NP \\
\hline DR*14:02 & 1 & 0.05 & 5 & 0.03 & 0.66 & 1.61 & $0.17-14.62$ \\
\hline OTHERS & NP & $\mathrm{NP}$ & 12 & 0.08 & 0.61 & 0.58 & $0.07-4.74$ \\
\hline \multicolumn{8}{|l|}{ DR1 } \\
\hline DR*01:01 & 1 & 0.05 & 1 & 0.007 & 0.08 & 8.29 & $0.49-138.70$ \\
\hline DR*01:03 & NP & $\mathrm{NP}$ & NP & NP & NP & $\mathrm{NP}$ & NP \\
\hline \multicolumn{8}{|l|}{ DR7 } \\
\hline DR*07:01 & NP & $\mathrm{NP}$ & 1 & 0.007 & 0.22 & 4.11 & $0.35-47.84$ \\
\hline \multicolumn{8}{|l|}{ DR5 } \\
\hline DR*11:01 & NP & NP & 1 & 0.007 & 0.22 & 4.11 & $0.35-47.84$ \\
\hline DR*11:04 & NP & NP & NP & NP & NP & NP & NP \\
\hline $\mathrm{DR} * 12: 01$ & NP & NP & NP & NP & NP & NP & NP \\
\hline OTHERS & $\mathrm{NP}$ & NP & $\mathrm{NP}$ & $\mathrm{NP}$ & NP & NP & NP \\
\hline \multicolumn{8}{|l|}{ DR3 } \\
\hline $\mathrm{DR} * 03: 011$ & NP & NP & $\mathrm{NP}$ & NP & NP & NP & NP \\
\hline OTHERS & $\mathrm{NP}$ & NP & $\mathrm{NP}$ & $\mathrm{NP}$ & NP & NP & NP \\
\hline \multicolumn{8}{|l|}{ DR9 } \\
\hline DR*09:01 & NP & NP & NP & $\mathrm{NP}$ & NP & NP & $\mathrm{NP}$ \\
\hline \multicolumn{8}{|l|}{ DR10 } \\
\hline DR10:01 & $\mathrm{NP}$ & NP & 1 & 0.007 & 0.22 & 4.11 & $0.35-47.84$ \\
\hline
\end{tabular}

$N$ : number of individuals; $n$ : number of alleles; g.f: gene frenquencies; *pC by Mantel- Haenszel method; OR: odds ratios; CI: confidence interval; NP: not presented.

[21] Vera-Cabrera L, Salinas-Carmona MC, Waksman N, et al. Host defenses in subcutaneousmycoses. Clin Dermatol, 2012,30(4):382-8.

[22] Sousa MG, Ghosn EE, Nascimento RC, et al. Monocytederived dendritic cells from patients with severe forms of chromoblastomycosis induce CD4 $\mathrm{T}$ cell activation in vitro. Clin Exp Immunol, 2009,156(1):117-25.

[23] Sadahiro A, Roque A, Shikanai-Yasuda MA. Generic human leukocyte antigen class II (DR $\beta 1$ and DQ $\beta 1$ ) alleles in patients with paracoccidioidomycosis. Med Myc, 2007,45(1):35-40.
[24] Carrillo-Meléndrez H, Ortega-Hernández E, Granados $\mathrm{J}$ et al. Role of HLA-DR alleles to increase genetic susceptibility to onychomycosis in nail psoriasis. Skin Appendage Disord, 2016,2(1-2):22-5.

[25] García-Romero MT, Granados J, Vega-Memije ME, et al. Analysis of genetic polymorphism of the HLA-B and HLA-DR loci in patients with dermatophyticonychomycosis and in their first-degree relatives. Actas Dermosifiliogr, 2012,103(1):59-62.

(Received 16 July 2018, Revised 13 September 2018, Accepted 19 September 2018) 